https://doi.org/10.7559/gestaoedesenvolvimento.2019.387

Data de receção: 15/04/2019 Data de aceitação: 22/07/2019

\title{
AUTONOMIA E FLEXIBILIDADE CURRICULAR: CAMINHOS E DESAFIOS NA AÇÃO EDUCATIVA
}

\section{AUTONOMY AND CURRICULAR FLEXIBILITY: PATHWAYS AND CHALLENGES IN EDUCATIONAL ACTION}

\author{
Sónia Alves ${ }^{1}$ orcid.org/0000-0001-7454-9707 \\ Olga Madanelo ${ }^{2}$ orcid.org/0000-0002-6320-7477 \\ Maria Martins ${ }^{3}$ orcid.org/0000-0001-5935-176X
}

\begin{abstract}
Resumo: Nas últimas décadas, a Escola portuguesa não só conseguiu ultrapassar os desafios do alargamento da escolaridade obrigatória, com também reduzir significativamente $o$ abandono e insucesso escolar; ainda assim, subsistem dificuldades na aplicação dos conhecimentos pelos alunos, o contexto socioeconómico permanece determinante no sucesso escolar e o desinteresse e indisciplina, aliados ao predomínio de metodologias pedagógicas tradicionais, continuam a afetar negativamente a aprendizagem. São estas debilidades que justificam a adoção de um paradigma educativo focado no desenvolvimento de competências adequadas aos desafios contemporâneos, para formar cidadãos com saberes diversificados, que sustentem a ação intencional e refletida.

$O$ Perfil dos Alunos à Saída da Escolaridade Obrigatória (PA) assegura a convergência das decisões de organização e gestão
\end{abstract}

\footnotetext{
${ }^{1}$ Docente do AE de Oliveira do Hospital, representante do CFAE Coimbra Interior na Equipa da Região Centro para a Autonomia e Flexibilidade Curricular - Despacho n. ${ }^{\circ}$ 9726/2018, de 17 de outubro. svsalves@ gmail.com

2 Docente do AE de S. Pedro do Sul, Hospital, representante do CFAE Castro Daire / Lafões na Equipa da Região Centro para a Autonomia e Flexibilidade Curricular Despacho n. ${ }^{\circ}$ 9726/2018, de 17 de outubro. olgamadanelo@gmail.com

${ }^{3}$ Docente do AE Infante D. Henrique, representante do CFAE Visprof na Equipa da Região Centro para a Autonomia e Flexibilidade Curricular - Despacho n. ${ }^{\circ}$ 9726/2018, de 17 de outubro. mariamartinssousa@gmail.com
} 
curriculares, nos diferentes percursos formativos, definindo princípios, valores e áreas de competências a desenvolver.

As Aprendizagens Essenciais explicitam os conteúdos indispensáveis, os processos cognitivos a ativar e o saber fazer associado; sugerem também ações estratégicas de ensino orientadas para as competências previstas no PA.

No novo currículo para o ensino básico e secundário (Decreto-Lei $n^{\circ}$ 55/2018, de 6 de julho), confere-se mais autonomia às Escolas para tomarem decisões que visem a melhoria da qualidade do ensino e aprendizagem, a efetivação da educação inclusiva, a implementação da coautoria curricular na gestão interdisciplinar do currículo, a educação para a cidadania $e$ desenvolvimento $e$ a integração da avaliação no desenvolvimento curricular.

A flexibilidade curricular pretende garantir a todos o direito à aprendizagem e ao sucesso educativo, pela adequação da ação educativa às especificidades do aluno e Escola, pela contextualização interdisciplinar dos saberes e pela promoção de aprendizagens ativas e significativas. Nos Domínios de Autonomia Curricular, o aluno é agente da construção de conhecimento pela ação, em ambientes de aprendizagem diferenciados e colaborativos.

A avaliação formativa assume uma função reguladora do ensino $e$ da aprendizagem, fundamentando adequações $e$ readaptações, e gera feedback sobre dificuldades $e$ potencialidades, promovendo a autorregulação das aprendizagens.

Palavras-chave: Autonomia e flexibilidade curricular, Perfil dos Alunos, Aprendizagem ativa.

Abstract: Nas últimas décadas, a Escola portuguesa não só conseguiu ultrapassar os desafios do alargamento da escolaridade obrigatória, com também reduzir significativamente o abandono e insucesso escolar; ainda assim, subsistem dificuldades na aplicação dos conhecimentos pelos alunos, o contexto socioeconómico permanece determinante no sucesso escolar $e$ o desinteresse $e$ 
indisciplina, aliados ao predomínio de metodologias pedagógicas tradicionais, continuam a afetar negativamente a aprendizagem. São estas debilidades que justificam a adoção de um paradigma educativo focado no desenvolvimento de competências adequadas aos desafios contemporâneos, para formar cidadãos com saberes diversificados, que sustentem a ação intencional e refletida.

In the last decades, the Portuguese Education System has overcome the challenges of extending compulsory education and reducing early school leaving and academic failure; nevertheless, students still reveal difficulties in applying their knowledge, the socioeconomic context remains determinant in academic success and, furthermore, disengagement and indiscipline issues, together with the predominance of traditional pedagogical methodologies, continue to negatively affect learning. These are the frailties that vindicate the adoption of an educational paradigm focused on the development of competences appropriate to contemporary challenges, in order to prepare citizens with various knowledges, which may sustain intentional and examined action.

The Students' Profile by the End of Compulsory Schooling (PA) ensures the convergence of curriculum organization and management decisions, in the different educational and training courses, defining principles, values and areas of competences to be developed.

The Essential Core curriculum identifies the common base and core curriculum all students should learn, as well as the cognitive processes to be activated and the associated know-how; it also suggests strategic educational actions focused on the Students' Profile competences.

With the new curriculum for compulsory education (Decreto-Lei $n{ }^{\circ}$ 55/2018, July 6), schools are granted more autonomy in order to make decisions aimed at improving the quality of teaching and learning, enhancing inclusive education, implementing curriculum co-authoring in interdisciplinary management and education for citizenship and development, and integrating evaluation in the curriculum development.

Curriculum flexibility aims to guarantee everyone the right to learning and school success, by adjusting the educational action to the specificities of the student and the school, by the interdisciplinary 
contextualization of knowledge and by promoting active and meaningful learning. In the "Curriculum Autonomy Domains", the student is the agent of his knowledge construction by action, in differentiated and collaborative learning environments.

The formative evaluation assumes a regulatory function of teaching and learning, supporting adaptations, generating feedback on difficulties and potentialities, and promoting students' self-regulation.

Keywords: Curriculum Flexibility and Autonomy, Students' Profile, Active Learning.

\section{INTRODUÇÃO}

Na história da Escola portuguesa, têm tido significativo sucesso as políticas educativas que visaram alargar a escolaridade obrigatória, garantir equidade no acesso à escola e proporcionar uma educação de qualidade, concedendo a todos as melhores oportunidades educativas. Porém, nela subsiste ainda um paradigma da ação educativa demasiadamente focada na transmissão e acumulação de informações, que tem vindo a revelar-se progressivamente inadequado a cenários sociais, laborais e pessoais cada vez mais dominados pela mudança acelerada e incerteza crescente quanto ao sentido da mesma. Na verdade, no início da Idade Moderna, pensadores como Montaigne defendiam já que o propósito último da educação devia ser a promoção da inteligência, através da individualização do ensino e da utilização de pedagogias em que o professor ajuda o aluno a descobrir o conhecimento (Gaspar e Ribeiro, 2016).

Os instrumentos enquadradores de referência - Perfil dos Alunos à Saída da Escolaridade Obrigatória (Martins et al., 2017), Aprendizagens Essenciais e o novo currículo para o ensino básico e secundário -, cujos princípios, normas e implicações na organização escolar e na gestão do currículo e do trabalho docente e discente pretendemos descrever e discutir neste artigo, constituem ferramentas criadoras de possibilidades de inovação e de flexibilização, no sentido da criação de ambientes e metodologias de aprendizagem que propiciem o desenvolvimento de 
competências diversas e a aquisição de múltiplas literacias, necessárias ao crescimento pessoal e à ação intencional e refletida no mundo atual.

\section{AS RESPOSTAS QUE A "VELHA" ESCOLA JÁ NÃO PODE DAR}

Ao longo das últimas três décadas, segundo Ferreira, Flores e Casas-Novas (2017a, 2017b), Justino e Santos (2017) e Marôco (2016), a Escola portuguesa tem vindo a desenvolver respostas institucionais, curriculares e pedagógicas que lhe têm permitido atingir níveis cada vez mais elevados de qualidade e eficiência: os professores portugueses são profissionais com elevadas habilitações e reconhecida eficácia; o alargamento da escolaridade obrigatória tem tido resultados positivos, tendo as taxas de abandono escolar precoce vindo a baixar de forma constante, bem como o número de alunos que repetem um nível de escolaridade; o desempenho dos alunos portugueses em provas internacionais (PISA, TIMMS e PIRLS) tem vindo a melhorar consistentemente, desde 2000. Por outro lado, embora no final da escolaridade obrigatória os alunos portugueses tenham desempenhos considerados adequados quanto à memorização de informações e procedimentos, sendo capazes de replicar conteúdos ou de aplicar estratégias de resolução rotineiras, quando esse é o objeto de avaliação, revelam maiores dificuldades em mobilizar e utilizar informações e procedimentos de forma não padronizada ou a raciocinar a partir deles, quando avaliados em operações cognitivas de nível superior (capacidade de síntese, de crítica, e estratégias de resolução de problemas) ou a capacidade de aplicar conhecimentos a situações novas (Sousa, 2017). Além disso, as taxas de insucesso escolar ainda são das mais elevadas da OCDE e o contexto socioeconómico de origem de um aluno permanece como fator determinante no seu sucesso escolar (Ferreira et al., 2017a, 2017b). Paralelamente, a falta de motivação e a adoção de comportamentos indisciplinados em sala de aula, por parte dos alunos, continuam a afetar negativamente a aprendizagem, situação que é também potenciada pelo predomínio de metodologias pedagógicas tradicionais, como aulas de cariz expositivo, e de práticas de avaliação sumativa por testagem, em detrimento de estratégias de aprendizagem ativa e da 
avaliação formativa, que potenciem o envolvimento do aluno (Ferreira et al., 2017a, 2017b; Justino e Santos, 2017; Trindade, 2018).

Sobressai, assim, a permanência de um paradigma educativo excessivamente centrado no conhecimento que urge substituir por um novo paradigma focado no desenvolvimento de competências mobilizadoras de conhecimento, de capacidades e de atitudes adequados a desafios contemporâneos, advindos do intenso ritmo de desenvolvimento do conhecimento científico e tecnológico, do crescimento exponencial da informação à escala global e da emergência ou reconfiguração de questões essenciais, relativas à identidade, à segurança, à sustentabilidade e à interculturalidade.

A Escola tem de responder às exigências destes tempos de imprevisibilidade e de mudanças, proporcionando ambientes de aprendizagem favoráveis ao desenvolvimento de competências, à aquisição de múltiplas literacias e à capacidade de aprendizagem ao longo da vida.

\section{NOVOS SABERES, OUTROS OLHARES, GRANDES DESAFIOS}

No paradigma de formação de cariz tradicionalista, ainda persistente, quer nas conceções, quer nas práticas educacionais, uma das grandes questões que se levanta à Escola atual está intrinsecamente relacionada com a nova possibilidade de um tipo de conhecimento menos segmentado e não estanque, que possa ser compreendido nas suas complexas relações com os contextos de produção, de formação-apropriação e de investigação através dos quais permanentemente se renova e legitima.

Estes "saberes para a ação", "saberes em ação" ou "saberes em uso" parecem apontar para a importância da formação de cidadãos através de saberes diversificados e atualizados que sustentem e informem a reflexão e a ação intencional e refletida.

De acordo com Cachapuz, Sá-Chaves e Paixão (2004:18), estes saberes não podem ser confundidos com a simples (mas indispensável) "aquisição de conhecimentos disciplinares (...), menos ainda com qualificações profissionais (...) que o progresso científico-tecnológico constantemente desactualiza". Podem e devem ser vistos como 
"competências fundacionais", que se deseja que todos os cidadãos desenvolvam para aprender ao longo da vida, "para agir de forma reflectida, consciente, informada e regulada por valores, que suportem a dignidade do humano, presente na sua diversidade individual, pessoal, social, cultural e civilizacional" (Cachapuz et al., 2004: 26). Ainda de acordo com Sá-Chaves (2007), são saberes da ordem da competência e não apenas da ordem da informação/conteúdo, ou seja, constituem-se como um elemento interfacial entre o conhecimento simples e a ação/intervenção, entre sujeito e ambiente, no espaço da mediação e através dela (Lerbet, 1986). Esta definição apresenta uma matriz marcadamente transdisciplinar, no sentido em que se trata de uma abordagem que propõe a construção de pontes entre as dimensões objetivas e as subjetivas, entre a ciência e a consciência, na compreensão do ser que aprende e no significado dessa aprendizagem para a sua humanização (Caraça, 2005). No essencial, aproxima-se da ideia de pensamento complexo (Lerbet, 1986, 1998, 2004; Le Moigne, 1996) sobre a construção da compreensão de objetos complexos, como é, neste caso, o conceito de competência.

Neste sentido, falar de competência pressupõe ter em consideração a estrutura interna dos sujeitos (conhecimentos, capacidades cognitivas, atitudes, emoções, valores e motivações) e os contextos educativos de natureza institucional e social com os quais esse mesmo sujeito interage, através dos seus desempenhos pessoais ou interpessoais. Por conseguinte, as competências não se desenvolvem em abstrato, apelam a conhecimentos multi e interdisciplinares que, por sua vez, dependem de "saberes básicos fundacionais, de modo a responder a questões cruciais que, desde sempre, perseguem e estimulam o pensamento humano na tentativa de encontrar melhores condições para a qualidade de vida e realização pessoal de todos" (Cachapuz et al., 2004:15).

De acordo com o exposto, os conceitos de competência e saberes constituem-se como um contínuo epistemológico, pois não existe competência sem os saberes que a informam, a sustentam e a qualificam e sem os valores que a legitimam socialmente.

É, também, neste sentido, que Cachapuz, Sá-Chaves e Paixão (2004:17) referem que o conceito "aprender a ser" é subordinante dos conceitos "aprender a conhecer", "aprender a fazer" e "aprender a viver 
juntos". Desta forma, validar processos educacionais através dos quais seja possível promover processos de construção coletiva de conhecimento pode ser de grande importância e ter consequências positivas na educação do século XXI.

Em vez de uma Escola preocupada apenas com a absorção passiva de informações, importa um outro modo de pensar a atividade pedagógica, na qual competências como aprender a pensar e a comunicar, a pesquisar, a intervir e a raciocinar logicamente e com sensibilidade humana, devem ser entendidas como objetivos fulcrais da Educação. Pode-se, assim, propiciar a construção efetiva de um novo quotidiano escolar, no qual uma nova didática possibilite que os temas a serem trabalhados em aula estejam inter-relacionados com a experiência prévia de cada um dos envolvidos num contexto sociocultural mais abrangente e mais significativo.

As mudanças ocorridas na sociedade conduzem, naturalmente, a alterações do conceito de currículo. Roldão (1999) e Sá-Chaves (2002) recolocam a questão da flexibilidade curricular quer no que se refere à dimensão instituída, de carácter macroestrutural e âmbito nacional, quer ao nível da sua gestão e desenvolvimento - dimensão instituinte, enquanto prática e exercício da relação educativa, contingente, aberta e reflexiva, para poder integrar a informação situacional no decurso da própria ação e, também, para que o professor possa adequar esta mesma ação às circunstâncias nela emergentes. O currículo, elaborado ao nível das estruturas macropolíticas (dimensão instituída), é concebido em função de objetivos e de indicadores gerais e das características médias da população-alvo, cujas propostas são iguais para todos.

Uma vez que a população escolar, em resultado da democratização do ensino, se apresenta cada vez mais heterogénea, considera-se que os processos de desenvolvimento curricular devem ser abertos, dinâmicos, modificáveis e evolutivos, para poderem ser melhorados ao longo do tempo (Sá-Chaves, 2002). Esta ideia de flexibilidade nos processos de ensino-aprendizagem tem também implicações na atividade docente, ou seja, o professor já não pode ser visto como alguém que apenas executa e cumpre as decisões emanadas do poder central, devendo ser reconhecido e reconhecer-se como um profissional, isto é, como um coconstrutor e gestor das propostas curriculares instituídas, tomando decisões sobre a sua 
ação de forma fundamentada, consciente e criticamente refletida (SáChaves, 2002) numa Escola que, no dizer de Alarcão (2000), se deve conceber coletivamente como instituição reflexiva.

Uma Escola para todos e em que todos são diferentes exige dos professores a capacidade para flexibilizar, através de processos de diferenciação (Cachapuz et al., 2004), na linha de um paradigma que proporcione o êxito e a mudança, sem despersonalizar e/ou aculturar, pois diversidade sem diferenciação pedagógica conduz à desigualdade. Neste reconhecimento da heterogeneidade e da diferença, impõe-se um diálogo intra- e interculturas, em que cada uma se valoriza através de práticas que permitem um melhor conhecimento de si e o (re)conhecimento dos outros.

De acordo com Cachapuz, Sá-Chaves e Paixão (2004) encontramo-nos perante um processo de internacionalização que reduziu as distâncias, diluiu as fronteiras e abriu o mundo. Hoje, cada homem, sem renegar a sua pátria, é cidadão do mundo. É nesta possibilidade dialógica entre visões e conceções diferentes, consensuais ou não, que sob uma perspetiva cidadã, se deseja uma efetiva relação de igualdade e pluralidade entre os sujeitos. Encontramo-nos perante um desafio da humanidade que consiste em construir um mundo para o qual é imprescindível deter novas competências para aprender a pensar e atuar, consubstanciadas nos saberes básicos, permitindo a possibilidade de um desenvolvimento equilibrado e harmonioso entre as pessoas e as sociedades consigo mesmas, com os outros e com o meio ambiente. Assim, será fundamental que consigamos articular, de forma reflexiva e crítica, os princípios da dignidade humana, da integridade da pessoa, da proteção e preservação da natureza, com o desenvolvimento científico-tecnológico.

Impõe-se, assim, (re)pensar a Escola como espaço público capaz de estimular, nas futuras (e atuais) gerações, novos modos de pensar a construção de Si num mundo mais justo ou, conforme Paulo Freire, (1993) mais humano e em que se prepare a materialização da grande utopia: unidade na diversidade. 


\section{AUTONOMIA E FLEXIBILIDADE CURRICULAR: RESPOSTAS PARA A (RE)CONSTRUÇÃO DA "NOVA" ESCOLA}

\subsection{Instrumentos Enquadradores de Referência - Quadro Normativo}

O Perfil dos Alunos à Saída da Escolaridade Obrigatória (PA), homologado pelo Despacho n. ${ }^{\circ}$ 6478/2017, de 26 de julho, foi concebido como uma matriz comum para todas as Escolas e ofertas educativas no âmbito da escolaridade obrigatória, ao nível curricular, no planeamento, na realização do ensino e da aprendizagem e na avaliação interna e externa da aprendizagem dos alunos. Constituindo um documento de referência para a organização de todo o sistema educativo, o PA deverá contribuir para a convergência e a articulação das decisões inerentes às várias dimensões do desenvolvimento curricular, quanto à organização e gestão curriculares e, ainda, à definição de estratégias, metodologias e procedimentos pedagógico-didáticos a utilizar na prática letiva.

O PA preconiza uma visão de aluno que, no término da escolaridade obrigatória, seja: detentor de múltiplas literacias, para analisar criticamente a realidade, avaliar e selecionar a informação, formular hipóteses e tomar decisões fundamentadas no seu dia a dia; livre, autónomo, responsável e consciente de si próprio e do mundo que o rodeia; capaz de lidar com a mudança e com a incerteza num mundo em rápida transformação; consciente da importância e do desafio oferecidos pelas Artes, Humanidades e Ciência e Tecnologia para a sustentabilidade social, cultural, económica e ambiental; capaz de pensar crítica e autonomamente, criativo, com competência de trabalho colaborativo e com capacidade de comunicação; apto a continuar a aprendizagem ao longo da vida, como fator decisivo do desenvolvimento pessoal e da intervenção social; conhecedor e respeitador dos princípios fundamentais da sociedade democrática e os direitos, garantias e liberdades em que esta assenta; respeitador da dignidade humana, do exercício da cidadania plena, da solidariedade para com os outros, da diversidade cultural e do debate democrático; hostil a todas as formas de discriminação e de exclusão social.

Aceitando a diversidade de percursos formativos possíveis na Escola portuguesa, o PA assegura a coerência do sistema de educação e dá 
sentido à escolaridade obrigatória, definindo os seus princípios, valores e áreas de competências a desenvolver.

Os princípios definidos no documento configuram uma Escola: humanista, visando a construção de uma sociedade mais justa, centrada na dignidade humana e na preservação do mundo; orientada para os saberes que sustentam a capacidade de decisão e de ação sobre as realidades naturais e sociais; promotora da aprendizagem ao longo da vida; inclusiva, garantindo o direito de acesso e participação plena e efetiva em todos os contextos educativos; com uma ação educativa coerente e flexível, trazendo a realidade para o centro das aprendizagens; capaz de se adaptar a novos contextos e estruturas e de atualizar conhecimentos e competências; defensora da sustentabilidade; capaz de incorporar a evolução do saber, com a estabilidade necessária para assegurar os efeitos desejados.

No que respeita aos valores, o PA determina que se incutam nos alunos a responsabilidade e integridade, a excelência e exigência, a curiosidade, reflexão e inovação, a cidadania e participação e a liberdade.

Quanto às competências a desenvolver por meio da ação educativa, elas são definidas como combinações complexas de conhecimentos (factuais, conceptuais, processuais e metacognitivos), capacidades (cognitivas e psicomotoras) e atitudes (associadas a habilidades sociais e organizacionais) que permitem a ação humana em contextos diversificados. As competências são, portanto, de natureza cognitiva e metacognitiva, social e emocional, física e prática, agregando-se em dez áreas: linguagens e textos; informação e comunicação; raciocínio e resolução de problemas; pensamento crítico e pensamento criativo; relacionamento interpessoal; desenvolvimento pessoal e autonomia; bemestar, saúde e ambiente; sensibilidade estética e artística; saber científico, técnico e tecnológico; consciência e domínio do corpo. Cada uma destas áreas de competências é explicitada através de um conjunto de descritores operativos, que clarificam os desempenhos pretendidos por parte dos alunos.

As Aprendizagens Essenciais (AE), homologadas para o ensino básico pelo Despacho n. ${ }^{\circ}$ 6944-A/2018, de 19 de julho, e para o Ensino Secundário (Cursos Científico-Humanísticos) pelo Despacho n. ${ }^{\circ} 8476-$ A/2018, de 31 de agosto, apresentam domínios nos quais se agregam 
conhecimentos, capacidade e atitudes, para cada área disciplinar e ano de escolaridade. Nestes documentos se explicitam, portanto, os conteúdos de conhecimento disciplinar indispensáveis, articulados concetualmente e significativos que os alunos devem saber, bem como os processos cognitivos que devem ativar para adquirir esse conhecimento e ainda o saber fazer a ele associado, num dado ciclo respetivo e na sua continuidade e articulação vertical (Roldão et al., 2017); sugerem-se também ações estratégicas de ensino orientadas para o PA, oferecendo exemplos de operacionalização diversa e elencam-se, ainda, descritores que remetem para as competências nele previstas.

Através da definição de um novo currículo para o ensino básico e secundário e dos princípios orientadores da avaliação das aprendizagens, no Decreto-Lei n. ${ }^{\circ}$ 55/2018, de 6 de julho, foi conferida mais autonomia às Escolas para tomarem decisões que ajudem os alunos a alcançar as competências do PA. Aquele normativo trouxe aos agentes educativos novos desafios: tornar a Escola um espaço culturalmente mais desafiante e significativo e educacionalmente mais ambicioso e influente; operacionalizar possibilidades de ação de cada Escola, de acordo com as características dos seus alunos e dos recursos humanos e materiais; implementar a componente curricular de Cidadania e Desenvolvimento, operacionalizando a Estratégia Nacional de Educação para a Cidadania (DGE/ME, 2017); adotar diferentes formas de organização do trabalho escolar por equipas educativas; possibilitar a adoção de um percurso formativo próprio no ensino secundário, através da permuta de disciplinas.

Os princípios orientadores que regem o novo currículo (Artigo $4 .^{\circ}$ do Decreto-Lei $n^{\circ} 55 / 2018$, de 6 de julho) incluem a melhoria da qualidade do ensino e da aprendizagem, através de uma abordagem multinível das necessidades educativas dos alunos, do reforço da autonomia das Escolas quanto a opções curriculares e do aumento do caráter formativo da avaliação, e a efetivação da educação inclusiva. Além disso, o novo currículo também preconiza: a implementação da coautoria curricular e da responsabilidade partilhada na gestão do currículo, assumindo-se os professores como agentes de desenvolvimento curricular e garantindo o envolvimento de alunos e encarregados de educação; a gestão e lecionação interdisciplinar e articulada do currículo, através da dinamização de projetos que aglutinam aprendizagens das diferentes 
disciplinas, planeados, realizados e avaliados em conjunto; a natureza transdisciplinar das aprendizagens; a educação para a cidadania e para o desenvolvimento; a integração da avaliação na gestão do currículo, ao serviço do ensino e das aprendizagens, assegurando a complementaridade entre avaliação interna e externa.

A flexibilidade curricular pretende, então, garantir a todos o direito à aprendizagem e ao sucesso educativo, aumentando a equidade e a inclusão, e melhorar a qualidade das aprendizagens, por via da adequação às especificidades do aluno e da Escola, da contextualização interdisciplinar dos conhecimentos, da valorização da aprendizagem centrada no aluno, da promoção de aprendizagens ativas e significativas e do desenvolvimento de competências complexas: questionar saberes, integrar conhecimentos, comunicar eficientemente e resolver problemas. Consequentemente, o sistema educativo deve implementar o desenvolvimento das competências de forma explícita e intencional, com mudanças deliberadas nos desenhos curriculares e nas práticas pedagógicas; estas alterações implicarão o abandono de um modelo disciplinar, uniformizador, de aprendizagem compartimentada e assente na transferência do conhecimento, em suma, um currículo de formato prescritivo, para adotar um modelo multidisciplinar de aprendizagem transformadora, alicerçado na diferenciação, na construção do conhecimento, na colaboração, na autonomia, na interdependência e na qualidade. Trata-se, portanto, de um currículo de formato orientativo, que integra o desenvolvimento de competências adequadas aos desafios da sociedade atual, preparando os alunos para um mundo global que valoriza a diferença e a ação autónoma e em relação com os outros e formando cidadãos inovadores, criadores e autónomos, com multiliteracias e capazes de pensar criticamente.

\subsection{Ferramentas Criadoras de Possibilidades}

\subsubsection{Flexibilidade na gestão do currículo}

O PA acarreta uma série de implicações práticas, no sentido de se alterarem as práticas pedagógicas para assegurar que as áreas de competência são trabalhadas em todas as componentes curriculares. $\mathrm{O}$ propósito essencial será o de adequar a ação educativa às finalidades do 
PA, através (i) da associação dos conteúdos a situações e problemas do quotidiano, (ii) da concretização de atividades de observação e questionamento da realidade, de integração de saberes e de confronto de perspetivas, resolução de problemas e de tomada decisões, (iii) da mobilização de técnicas de trabalho, materiais e recursos diversificados, (iv) do desenvolvimento de atividades cooperativas de aprendizagem, com troca de saberes, e de projetos intra ou extraescolares, (v) da utilização crítica de fontes de informação diversas e das TIC, (vi) da promoção da intervenção livre e responsável dos alunos e (vii) da valorização da livre iniciativa e da intervenção positiva no meio e na comunidade.

A construção das AE pretendeu, essencialmente, minorar dificuldades e constrangimentos advindos da extensão dos documentos curriculares vigentes, de modo a permitir o aprofundamento de temas, a consolidação de aprendizagens de forma efetiva, o desenvolvimento de competências mais complexas (pesquisa, análise, debate e reflexão), que requerem mais tempo, e a concretização de diferenciação pedagógica na sala de aula. Além disso, as AE visam, também, potenciar explorações interdisciplinares diversificadas, através de um conjunto essencial de conteúdos, capacidades e atitudes a trabalhar de forma articulada nos domínios de autonomia curricular. Consequentemente, a operacionalização das AE deve basear-se na valorização e diversificação do trabalho prático, no apelo à investigação e à exploração de diferentes formas de resolução de problemas, na análise de temáticas científicas atuais e pertinentes para os alunos, no desenvolvimento do trabalho colaborativo e no apoio e complementaridade do trabalho desenvolvido nas diferentes disciplinas, valorizando a interdisciplinaridade e a transdisciplinaridade, bem como a atividade e o protagonismo intelectual dos alunos, apoiados no domínio de saberes culturalmente validados, que são as referências e metas da ação educativa. Com efeito, caberá à Escola, enquanto contexto de desenvolvimento de competências cognitivas e metacognitivas, sociais e relacionais, tecnológicas e instrumentais, estéticas e éticas, a função de desafiar a ampliar os saberes e a desenvolver as competências, beneficiando do património de informações, instrumentos, procedimentos e atitudes culturalmente validado. Neste sentido, a gestão do currículo deverá orientar-se para a construção de 
desafios educativos, em função de projetos e problemas que justifiquem a mobilização do património de conhecimentos, capacidades e atitudes das várias áreas do saber (disciplinar) e para a organização de atividades de aprendizagem que incentivem processos de construção, partilha e discussão de respostas a questões intelectualmente produtivas. Desta forma, o conhecimento construído será um instrumento da ação de cada um no mundo, permitindo a intencionalidade da mesma, e a Escola assumir-se-á como um espaço gerador de possibilidades de compreender e de agir no mundo.

Como determinado no artigo 19. ${ }^{\circ}$ do Decreto-Lei $n^{\circ}$ 55/2018, de 6 de julho, as prioridades no planeamento curricular centrar-se-ão nas áreas de competências do PA, valorizando as artes, as ciências, o desporto, as humanidades e as TIC, bem como o trabalho prático e experimental (com desdobramento de turmas ou outra organização) e o desenvolvimento de competências de pesquisa, avaliação, reflexão, mobilização crítica e autónoma de informação, para resolução de problemas e reforço da autoestima; deverá, também, considerar-se a integração de componentes curriculares de natureza regional e da comunidade local; finalmente, promover-se-ão experiências de comunicação e expressão multimodais e o exercício da cidadania ativa e participação social, em contextos de partilha, colaboração e confronto de ideias. A gestão flexível do currículo deve, igualmente, assentar na implementação de trabalho de projeto, centrado nos alunos enquanto autores e promotor de aprendizagens significativas, e na concretização de domínios de autonomia curricular, com combinação parcial ou total de disciplinas, promovendo tempos de trabalho interdisciplinar, com alternância de períodos de funcionamento disciplinar e multidisciplinar, em trabalho colaborativo, e integrando projetos desenvolvidos na Escola no horário semanal, de forma rotativa ou outra.

As dinâmicas pedagógicas a adotar (Artigo 21. ${ }^{\circ}$ do Decreto-Lei $\mathrm{n}^{\circ}$ 55/2018, de 6 de julho) deverão privilegiar o trabalho de articulação disciplinar, operacionalizado por equipas educativas em função da especificidade da turma ou grupos de alunos, uma atuação preventiva, para antecipar e prevenir insucesso e abandono escolares, por meio da adequação, diversidade e complementaridade das estratégias de ensino e aprendizagem, a implementação de medidas multinível de suporte à 
aprendizagem, universais, seletivas e adicionais, ajustadas à aprendizagem e inclusão, e a produção de informação descritiva sobre os desempenhos dos alunos. As atividades de aprendizagem desenrolar-seão em grupos de trabalho para aquisição, desenvolvimento e consolidação de aprendizagens específicas, para apoio ao estudo, privilegiando a pesquisa, tratamento e seleção de informação, e para o desenvolvimento de trabalho autónomo, interpares, com mediação de professores.

É fundamental que se garanta o envolvimento dos alunos, com foco na intervenção cívica, livre iniciativa, autonomia, responsabilidade e respeito pela diversidade, e a rentabilização de recursos e oportunidades da Escola e da comunidade. Deve, ainda, ser assegurada a regularidade da monitorização da intencionalidade e do impacto das estratégias e medidas.

No âmbito da ação educativa, são também propostas as tutorias, visando a autorregulação das aprendizagens e a adaptação às expectativas académicas e sociais dos alunos, as ações de orientação escolar e profissional e de apoio ao crescimento e desenvolvimento pessoal e social, à promoção da saúde e à prevenção de comportamentos de risco.

\subsubsection{Flexibilidade na gestão autónoma do trabalho docente}

O novo currículo para o ensino básico e secundário institui os professores enquanto agentes do desenvolvimento curricular, na reflexão sobre as opções a tomar, tendo em vista a adequação aos contextos, e sobre a sua exequibilidade, bem como na sua avaliação (alínea d) do número 1 do artigo $4 .^{\circ}$ do Decreto-Lei $n^{\circ} 55 / 2018$, de 6 de julho). A flexibilidade curricular implica, portanto, uma mudança no papel do professor, o qual, segundo Cosme (2009), deverá assumir-se como um interlocutor qualificado do aluno no seu processo de construção de conhecimento; deste modo, caberão ao professor a organização de ambientes de aprendizagem, a dinamização das situações de trabalho e de aprendizagem, o apoio direto ao aluno durante a realização das tarefas de aprendizagem e o estímulo e apoio à reflexão sobre as mesmas. Tais funções implicam que, a par de uma sólida formação científica, os professores deverão ser profissionais reflexivos, autónomos e detentores de um espírito colaborativo e aberto à mudança e à inovação profissional (Dias e Ribeiro, 2015). 
Outro requisito da flexibilidade curricular é a efetivação do trabalho colaborativo docente, em três vertentes: a coadjuvação, a permuta temporária e o trabalho em equipas educativas, grupos de docentes de diferentes áreas disciplinares que lecionam à(s) mesma(s) turma(s). Estas equipas, constituídas por conselho de turma, por conjunto de turmas ou por ano de escolaridade, responsabilizam-se pela gestão e configuração articulada do currículo a ser apreendido, trabalhando em conjunto nas diferentes fases do processo de ensino e aprendizagem, bem como de avaliação, preferencialmente através de canais de comunicação e plataformas digitais.

A constituição de equipas educativas funcionais permitirá rentabilizar o trabalho dos professores e aumentar a sua eficácia; Boavida e Ponte (2002) atribuem à colaboração melhorias significativas nas práticas docentes, na medida em que propicia a articulação de diferentes visões e experiências, resultando em maior criatividade, inovação e eficácia, pois não só proporciona maior diversificação de estratégias pedagógicas, como aumenta os níveis de confiança e autoeficácia, quanto à experimentação de novas práticas, aumenta a reflexão sobre as mesmas e oferece uma rede de apoio para enfrentar incertezas e retrocessos. $\mathrm{O}$ trabalho colaborativo docente permite evitar a culpabilização perante um problema, vendo-o, antes, como um obstáculo a ultrapassar, com as competências e determinação coletivas. $\mathrm{O}$ trabalho colaborativo docente é, portanto, um processo marcado pela responsabilização conjunta, pela negociação e pela tomada de decisões, visando a melhoria do conhecimento profissional e a maior eficácia do desempenho (Abelha, 2011; Bastos, 2015; Boavida e Ponte, 2002; Palmeirão e Alves, 2017; Roldão, 2007b;)

Além de permitir a reflexão, planificação, execução e avaliação coletivas, o trabalho colaborativo em equipa educativa também possibilita reduzir o número de professores por turma e concretizar um acompanhamento mais próximo aos alunos. Cabem às equipas educativas funções nucleares, como sejam definir as dinâmicas de trabalho pedagógico adequadas às especificidades da turma, assegurar a gestão das dinâmicas pedagógicas a implementar, envolver os alunos no planeamento, na realização e na avaliação das aprendizagens, operacionalizar o trabalho de natureza interdisciplinar e de articulação disciplinar, avaliar o impacto das estratégias adotadas e produzir 
dispositivos de informação dirigida aos alunos e encarregados de educação, como apoio às aprendizagens e à autorregulação.

\subsubsection{Flexibilidade na gestão integradora do trabalho dos alunos}

A flexibilidade na gestão integradora das atividades de aprendizagem pode concretizar-se nos Domínios de Autonomia Curricular (DAC) (alínea e) do artigo 3. ${ }^{\circ}$ do Decreto-Lei $n^{\circ}$ 55/2018, de 6 de julho), os quais constituem uma opção de trabalho interdisciplinar, através da combinação total ou parcial de componentes do currículo, articulando AE de diferentes áreas disciplinares de um mesmo ano de escolaridade. Nos DAC, a planificação e operacionalização do ensino e aprendizagem ocorrem colaborativamente, pela equipa educativa, a qual também decide as técnicas e instrumentos de monitorização e de avaliação a aplicar, de modo a gerar dados e feedback sobre os desempenhos em cada disciplina. Um DAC permite desenvolver as áreas de competências do PA, pela integração dos saberes e pela adoção de trabalho prático e experimental e de metodologias de aprendizagem ativa, que estimulam o envolvimento, responsabilidade e tomada de decisões por parte do aluno, desenvolvem as capacidades de pesquisa, relação e análise e promovem aprendizagens ativas e significativas.

Na planificação de um DAC, a equipa educativa deve identificar linhas de confluência das $\mathrm{AE}$ de várias disciplinas e definir a intencionalidade pedagógica e curricular da articulação das atividades de aprendizagem a propor aos alunos - Que conteúdos integrar? Para trabalhar que competências? A partir de que problema ou desafio inicial? Através de que atividades?

$\mathrm{Na}$ etapa de execução, a equipa selecionará metodologias de aprendizagem ativa, que promovam a autonomização da aprendizagem, a colaboração e a inclusão, nomeadamente, aula invertida, trabalho de projeto, aprendizagem baseada em problemas, aprendizagem por investigação, aprendizagem por descoberta guiada ou estudos de caso; assim, o aluno tornar-se-á agente da construção de conhecimento pela ação, com orientação do professor, o seu interlocutor qualificado (Cosme, 2009), ou de intervenientes externos, em ambientes de aprendizagem diferenciados e intencionais. 
A monitorização e avaliação dos desempenhos e dos resultados alcançados também será decidida pela equipa educativa, que definirá técnicas, instrumentos e procedimentos avaliativos diversificados e adequados às finalidades, destinatários e objeto(s) da avaliação, bem como ao tipo de informação a recolher, para a avaliação nos domínios específicos de cada disciplina.

Considerando que a gestão contextualizada e flexível do currículo pressupõe uma rotura com o ensino simultâneo, apoiado no "mito da homogeneidade" dos estilos e ritmos de aprendizagem dos alunos, ela assentará em práticas educativas que promovam a participação, a colaboração e a autonomia; segundo Cosme (2017), o trabalho de projeto constitui um campo favorável ao desenvolvimento de aprendizagens ativas, significativas, colaborativas e de natureza interdisciplinar, desde que a sua conceção, planificação, implementação e avaliação estejam subordinadas ao sucesso das aprendizagens: o projeto é uma estratégia para a aprendizagem contextualizada e coerente. Este propósito implica que se parta de um problema desafiante, significativo e exequível para os diferentes elementos do grupo de trabalho, que se promova a participação de todos os elementos do grupo de trabalho na definição das estratégias de abordagem e na realização do trabalho de projeto e que se definam mecanismos de regulação e autorregulação que promovam a autonomia dos alunos.

Cosme (2018) e Rodrigues (2018) esclarecem que um projeto interdisciplinar pode articular-se a partir de uma temática comum ao património de várias disciplinas, ou explorar instrumentos e procedimentos de construção de conhecimento mobilizados em diversas disciplinas ou, ainda, assentar num ou mais géneros textuais, como base de articulação curricular; o trabalho de projeto pode orientar-se para a criação de um produto ou evento ou visar a realização de experiências de aprendizagem que integrem saberes de diferentes áreas. As autoras enumeram múltiplos exemplos de projetos interdisciplinares, como campanhas de sensibilização ou de intervenção na comunidade, produção de conteúdos multimédia a divulgar na comunidade educativa, a organização de saraus, exposições ou semanas culturais, os intercâmbios culturais e científicos ou as candidaturas a prémios de âmbito local, nacional ou internacional (Cosme, 2018; Rodrigues, 2018). 
O projeto não é um fim, mas um meio para otimizar as aprendizagens. Como tal, deve visar a abordagem dos conteúdos curriculares e o desenvolvimento das competências do PA; deve ter sentido e intencionalidade pedagógica, partindo de um problema ou questão relevante, do contexto ou do interesse dos alunos; deve desencadear o questionamento ativo e a seleção e aplicação de soluções e recursos; deve provocar a tomada de decisões; deve gerar reflexões conjuntas sobre as aprendizagens, os obstáculos encontrados e as formas de os superar; deve originar revisão e feedback, pelo professor e pelos pares, que os alunos usarão para melhorarem o processo e os produtos; pode prever uma partilha pública, incentivando a participação e ação cívica no mundo (Cabral, 2019, 20 de março; Cohen e Fradique, 2018).

Como explica Cosme (2018), a aprendizagem baseada na resolução de problemas assenta em atividades sobre temas aglutinadores, que funcionam como fontes de problemas para o desenvolvimento do currículo. Cabe à equipa educativa definir os objetivos de aprendizagem que regem os problemas a propor aos alunos, para provocar a mobilização desafiante do conhecimento. Os professores devem selecionar problemas impossíveis de resolver sem que se realizem determinadas aprendizagens; devem também prever as atividades a concretizar para que as aprendizagens desejadas se realizem necessariamente e os dispositivos a organizar para que os alunos possam concluí-las. Os problemas geradores de aprendizagem resultarão de preocupações e interesses dos alunos ou neles induzidos, de forma a envolvê-los em investigação colaborativa, promovendo a curiosidade, o raciocínio, a autonomia e a organização. A aprendizagem adquirirá um caráter integrador, com foco no processo e efetivada por via de processos de investigação experimental. $\mathrm{O}$ aluno assume-se, assim, como agente de um processo natural de aprendizagem, no qual decide objetivos, sentido e ritmo do trabalho, com o apoio do professor enquanto organizador e orientador das atividades.

Dinâmicas pedagógicas como as referidas permitem que a ação educativa se centre no trabalho diferenciado de aprendizagem dos alunos, em colaboração, e não no ensino expositivo simultâneo, pelo professor; ocorre, então, a transição de um paradigma de competição interpares e de comunicação vertical para outro de trabalho colaborativo e parcerias interpares. Como refere Tomlinson (2008), a turma, juntamente com o(s) 
professor(es), constitui-se como comunidade de aprendizagem, na qual o conhecimento se constrói interativa e coletivamente, pela atividade conjunta, sendo as aprendizagens realizada pela ação conjunta.

$\mathrm{Na}$ aprendizagem colaborativa, podem adotar-se múltiplas modalidades de trabalho, de modo a que cada aluno, de acordo com as suas características, usufrua ao máximo dos recursos disponíveis (Pereira, 2018); caberá ao professor clarificar as expectativas quanto à sua participação do aluno no trabalho de grupo, explicitar os critérios e instrumentos de avaliação da competência de colaboração e fornecer feedback frequente, para autorregulação de desempenhos e atitudes.

Por sua vez, a avaliação, enquanto processo regulador do ensino e da aprendizagem, deve revestir natureza eminentemente formativa, de forma a fundamentar adequações e readaptações no ensino e aprendizagem e a gerar feedback sobre dificuldades e potencialidades sentidas ou detetadas, com o propósito de envolver os alunos na autorregulação das aprendizagens e a fornecer informação aos encarregados de educação.

A avaliação pedagógica ou avaliação para as aprendizagens (Domingues, 2011, 2013, 2014) é um processo contínuo de recolha de informação, análise dos dados recolhidos e reflexão sobre os mesmos, ao longo da aprendizagem, com o objetivo de a melhorar; assumindo-se como uma componente da gestão do currículo com uma função reguladora, ao serviço da aprendizagem, a avaliação pedagógica não pode ser um meio de exclusão, mas sim um instrumento de promoção do sucesso, pautado pelo rigor, intencionalidade, sistematicidade, continuidade e diversidade de métodos, instrumentos e agentes. A avaliação será tanto mais rigorosa e fiável quanto for realizada conjuntamente por professor(es) e aluno(s), que se envolve(m) ativamente no processo, consciente(s) dos objetivos, critérios de avaliação e desempenhos a alcançar, que participa $(m)$ na definição de metas para monitorizar o seu desenvolvimento, que reflete $(\mathrm{m})$ sobre os resultados e assume $(\mathrm{m})$ a responsabilidade de se desenvolver e alcançar o sucesso expectável; deste modo, a avaliação para as aprendizagens também funciona como um processo de aprendizagem em si mesma. A intencionalidade das práticas avaliativas determina o tipo de informação a recolher e os momentos e formas dessa recolha em função da finalidade da mesma. A sistematicidade e continuidade assentam na diversidade de 
técnicas, instrumentos e processos e no facto de incidir no que é observável, em situações em que o aluno demonstre as competências em ação. Com efeito, as tarefas propostas ao aluno têm de ter um triplo propósito: ajudar o aluno a aprender, ajudar o professor a ensinar e ajudar ambos a avaliar as aprendizagens.

O feedback é o elemento central da avaliação pedagógica, pois permite clarificar as metas da aprendizagem, detetar sucessos e dificuldades de aprendizagem e perceber as medidas e o trabalho a realizar para o aluno atingir os seus objetivos. O feedback torna-se, portanto, o real conteúdo da avaliação pedagógica, fundamentando a regulação do ensino pelo professor e a autorregulação da aprendizagem pelo aluno.

\section{CONCLUSÃO}

A Autonomia e Flexibilidade Curricular, na essência, possibilitam diferentes caminhos para ultrapassar desafios diversos. É neste contexto, então, que importa repensar as funções da Escola e a natureza da ação educativa, no sentido de as colocar sempre e cada vez mais ao serviço da formação das novas gerações para a compreensão, interação e ação no mundo social e natural.

Resta-nos procurar todas as possíveis coerências, procurando compreender os desacertos das músicas separadas e a harmonia do som da orquestra (Martins Barata, 2005).

\section{FONTES E BIBLIOGRAFIA}

Abelha, M. (2011). Trabalho colaborativo docente na gestão do currículo do Ensino Básico: do discurso às práticas. Tese de Doutoramento em Didática. Aveiro: Universidade de Aveiro. Disponível em http://hdl.handle.net/10773/3718

Bastos, F. (2015). Trabalho colaborativo entre docentes num território educativo de intervenção prioritária. Estudo de caso. Tese (Doutoramento em Educação) Universidade Portucalense Infante Dom Henrique. Disponível em http://hdl.handle.net/11328/1301 
Boavida, A. \& Ponte, J. (2002). Investigação Colaborativa: Potencialidades e Problemas. Disponível em

http://www.educ.fc.ul.pt/docentes/jponte/docs-pt\%5C02-BoavidaPonte(GTI).pdf

Cabral, I. (2019, 20 de março). Metodologia de trabalho de projeto aprendizagem significativa ou mero show off? Disponível em https://ilidiacabral.weebly.com/educere/metodologia-de-trabalho-deprojeto-aprendizagem-significativa-ou-mero-show-off

Caraça, J. (2005). Compreender as paixões, amar as razões. Comunicação apresentada no Ciclo de Seminários/Conferências "Espelhamento, Interrogação e Metamorfose" realizado no âmbito do Curso de Doutoramento de Base Curricular em Didática. Aveiro: DDT Universidade de Aveiro.

Cohen, A. C., Fradique, J. (2018). Guia da Autonomia e Flexibilidade Curricular. Lisboa: Raiz Editora.

Cosme, A. (2009). Ser professor: a acção docente como uma acção de interlocução qualificada. Porto: Livpsic.

Cosme, A. (2017). Apresentação da articulação curricular e interdisciplinaridade: contributo para uma reflexão. Disponível em https://www.dge.mec.pt/sites/default/files/Curriculo/Projeto_Autono mia_e_Flexibilidade/articulacaocurricular_aveiro.pdf

Cosme, A. (2018). Autonomia e Flexibilidade Curricular. Propostas e estratégias de ação. Porto: Porto Editora.

Decreto-Lei n. ${ }^{\circ}$ 55/2018, de 6 de julho -Estabelece o currículo dos ensinos básico e secundário e os princípios orientadores da avaliação das aprendizagens. Disponível em https://data.dre.pt/eli/declei/55/2018/07/06/p/dre/pt/html

Dias, P. A., Ribeiro, C. (2015). Supervisão pedagógica e crescimento profissional no processo de avaliação de desempenho docente. Revista Gestão e Desenvolvimento, 23 (2015), 125-154.

Estratégia Nacional de Educação para a Cidadania. (2017). Lisboa: DGE/Ministério da Educação. 
Fernandes, D. (2011). Articulação da aprendizagem, da avaliação e do ensino: questões teóricas, práticas e metodológicas. Porto Editora. Disponível em http://repositorio.ul.pt/handle/10451/6988

Fernandes, D. (2013). Avaliação em educação: uma discussão de algumas questões críticas e desafios a enfrentar nos próximos anos. Ensaio: Avaliação e Políticas Públicas em Educação, 21(78), 11-34. Disponível em http://www.scielo.br/pdf/ensaio/v21n78/aop_0113.pdf

Fernandes, D. (2014).Avaliação das aprendizagens e políticas educativas: o difícil percurso da inclusão e da melhoria. In M. L. Rodrigues (Org.) (2014). Quarenta anos de políticas de educação em Portugal: A construção do sistema democrático de ensino. Volume I. Coimbra: Almedina, 231-268. Disponível em

http://repositorio.ul.pt/bitstream/10451/16010/1/DFernandes_Almedi na.pdf

Ferreira, A. S., Flores, I., Casas-Novas, T. (2017a). Introdução ao estudo - Porque melhoraram os resultados PISA em Portugal? Estudo longitudinal e comparado (2000-2015). Lisboa: Fundação Francisco Manuel dos Santos.

Ferreira, A. S., Flores, I., Casas-Novas, T. (2017b). Porque melhoraram os resultados PISA em Portugal? Estudo longitudinal e comparado (2000-2015). Lisboa: Fundação Francisco Manuel dos Santos.

Freire, P. (1993). Política e Educação. São Paulo: Cortez Editores.

Gaspar, H., Ribeiro, H. (2016). "A pedagogia - ao longo dos tempos". Revista Gestão e Desenvolvimento, 24 (2016), 191-211.

Justino, D., Santos, M. E. B. (2017). Estado da Educação 2016. Lisboa: CNE.

Marôco, J. (Coord.) (2016). PISA 2015 - Portugal Volume I: Literacia Científica, Literacia de Leitura \& Literacia Matemática (Vol. I). Lisboa: Instituto de Avaliação Educativa.

Martins Barata, J. P. (2005). As Ciências da Complexidade, sinal ou motor da vontade de Unificação Cultural, Comunicação apresentada no Ciclo de Seminários/Conferências "Espelhamento, Interrogação e Metamorfose" realizado no âmbito do Curso de Doutoramento de Base Curricular em Didáctica. Aveiro: DDT - Universidade de Aveiro. 
Martins, G. O., Gomes, C. S., Brocardo, J. L., Pedroso, J. V., Acosta Carrillo , J. L., Ucha, L. M., Encarnação, M., Horta, M. J., Calçada, M. T., Nery, R. V., Rodrigues, S. V. (2018). Perfil dos Alunos à Saída da Escolaridade Obrigatória. Lisboa: Ministério da Educação. Homologado pelo Despacho n. ${ }^{\circ}$ 6478/2017, de 26 de julho. Disponível em

https://dge.mec.pt/sites/default/files/Curriculo/Projeto_Autonomia_e _Flexibilidade/perfil_dos_alunos.pdf

Mendonça, A. T. P., Cosme, A. (2018). "A transformação das práticas profissionais docentes tendo como referência a metodologia TELESSALATM”. Revista Práxis Educacional, Vitória da Conquista - Bahia - Brasil, v. 14, n. 30, 376-392, out./dez. 2018. DOI: https://doi.org/10.22481/praxis.v14i30.4373

Palmeirão, C., Alves, J. M. (Coord.) (2017). Construir a autonomia e a flexibilização curricular: os desafios das Escolas e dos professores. Porto: Universidade Católica Editora.

Pereira, F. (Coord.) (2018). Para Uma Educação Inclusiva - Manual de Apoio à Prática. Lisboa: Ministério da Educação/Direção-Geral da Educação (DGE).

Rodrigues, S. V. (2018). "Três modos de organizar sequências de aprendizagem interdisciplinares com base nas Aprendizagens Essenciais". Disponível em

http://www.dge.mec.pt/sites/default/files/boletim/aprendizagens_esse nciais_consolidacao-articulacao.pdf

Roldão, M. C. (2007). Colaborar é preciso: Questões de qualidade e eficácia no trabalho dos professores. Revista Noesis, 71, 24-29.

Roldão, M. C., Almeida, S. (2018) . Gestão Curricular Para a Autonomia das Escolas e Professores. Ministério da Educação / Direção-Geral da Educação (DGE).

Roldão, M. C., Peralta, H., Martins, I. P. (2017). Para a Construção de Aprendizagens Essenciais Baseadas no Perfil dos Alunos. Disponível em

http://www.dge.mec.pt/sites/default/files/Curriculo/Projeto_Autonom ia_e_Flexibilidade/ae_documento_enquadrador.pdf 
Sá-Chaves, I. (2007). A interligação dos conceitos de Didáctica, Avaliação e Supervisão na acção pedagógica. Uma perspectiva de (re)configuração epistemológica. In A. Lopes (Org) (2007). De uma Escola a outra: temas para pensar a formação inicial de professores. Porto: Afrontamento, 51-62.

Sousa, H. D. (Dir.) (2017). Exames Finais Nacionais - Ensino Secundário, Relatório Nacional: 2010-2016. Lisboa: IAVE.

Tomlinson, C. A (2008). Diferenciação pedagógica e diversidade. Porto: Porto Editora.

Trindade, R. (2018). Autonomia, flexibilidade e gestão curricular: relatos de práticas. Lisboa: Leya Educação.

Trindade, R., Cosme, A. (2016). Instruir, aprender ou comunicar: Reflexão sobre os fundamentos das opções pedagógicas perspetivadas a partir do ato de ensinar. Rev. Diálogo Educ., Curitiba, v. 16, n. 50, 1031-1051, out./dez. 2016. http://dx.doi.org/10.7213/1981416X.16.050.AO01 